\title{
An omission procedure reorganizes the microstructure of sign-tracking while preserving incentive salience
}

\author{
Stephen E. Chang and Kyle S. Smith \\ Department of Psychological and Brain Sciences, Dartmouth College, Hanover, New Hampshire 03755, USA
}

\begin{abstract}
Appetitive sign-tracking, in which reward-paired cues elicit approach that can result in cue interaction, demonstrates how cues acquire motivational value. For example, rats will approach and subsequently interact with a lever insertion cue that signals food delivery upon its retraction. However, lever deflections are rapidly reduced once rats are trained on an omission schedule in which lever interactions cancel food delivery. Here we evaluated the change in sign-tracking response topography in rats exposed to such an omission procedure. Lever deflections dropped precipitously when they canceled reward. However, rats that were on an omission schedule continued to approach, sniff, and contact the lever without pressing it, and did so at comparable rates to rats that were not under an omission schedule. Thus, sign-tracking was maintained, albeit in a different manner, following omission. Such findings show that the motivational attraction to reward cues can be expressed with remarkable persistence and flexibility.
\end{abstract}

[Supplemental material is available for this article.]

Appetitive sign-tracking is a phenomenon in which a rewardpaired cue elicits approach that can result in cue interaction (Brown and Jenkins 1968; Jenkins and Moore 1973; Hearst and Jenkins 1974; Boakes 1977). For example, rats will acquire a conditioned response (CR) in which they will approach, contact, and bite a lever conditioned stimulus (CS) that signals the delivery of a food unconditioned stimulus (US). Sign-tracking is a key model for studying behavioral and neural mechanisms of normal and excessive motivational attraction to reward-paired stimuli (Lajoie and Bindra 1976; Berridge 2004; Tomie et al. 2008; Flagel et al. 2010; Robinson and Berridge 2013; Huys et al. 2014; Robinson et al. 2014).

Negative automaintenance, in which a lever press cancels reward, has been used to show that sign-tracking can be markedly sensitive to instrumental contingency changes (Williams and Williams 1969; Stiers and Silberberg 1974; Locurto et al. 1976), suggesting a sensitivity to response-reward associations (Skinner 1992). For example, Locurto et al. (1976) have found that lever contacts after sign-tracking are markedly reduced in rats moved to an omission schedule, with similar rates of lever contacts compared with rats exposed to extinction or random cue/reward delivery. However, typically, sign-tracking does not decline to zero (Atnip 1977; Eldridge and Pear 1987; Schwartz and Williams 1972a; Stiers and Silberberg 1974; Woodard et al. 1974), suggesting some motivational persistence as well. Thus, sign-tracking CRs may be partly sensitive to contingency and partly under control of motivational forces that promote its persistence.

Generally, it remains unclear to what quantitative extent the motivational attraction to the CS actually declines along with the declining CR when it cancels reward. Is the incentive value of the CS retained but masked by reduced lever pressing measures, or is it reduced as well?

To clarify this issue, we studied the response topography of sign-tracking CRs under negative automaintenance, as lever depressions are only one aspect of sign-tracking (Hearst and Jenkins 1974). Indeed, sign-tracking components can be ex-

\section{Corresponding author: Stephen.Chang@dartmouth.edu} Article is online at http://www.learnmem.org/cgi/doi/10.1101/Im.041574.115. pressed differently in sign-tracking and negative automaintenance conditions (Schwartz and Williams 1972b; Stiers and Silberberg 1974; Locurto et al. 1976; Davey et al. 1981), as well as when motivational processes are enhanced by brain manipulations (Mahler and Berridge 2009). Thus, we evaluated how signtracking may persist through differential expression of CRs.

Rats $(n=10)$ that had acquired a discriminative sign-tracking response were exposed to conditions in which lever depression led to reward cancellation (Supplemental Methods). These rats were the "sham" group used in a published experiment on the effects of accumbens lesions on sign-tracking acquisition (Chang and Holland 2013). The rats were restricted to $85 \%$ of pretask weights throughout the study. They were first trained on a task in which insertion of a CS+ lever for 10 -sec predicted reward $(0.1 \mathrm{~mL}$ of $8 \%$ sucrose) in a food cup following its retraction. A second CS - lever was inserted similarly on different trials, but did not predict reward. Within each 64-min session, there were $25 \mathrm{CS}+$ and $25 \mathrm{CS}-$ trials (mean ITI $=77 \mathrm{sec}$; randomized order; lever assignment counterbalanced). Over the course of 12 training sessions, rats developed a robust sign-tracking $\mathrm{CR}$ to the $\mathrm{CS}+$. Rats in Group Omission ( $n=5$ ) were then exposed to negative automaintenance conditions for 12 more days, during which CS+ lever depression canceled reward delivery. Rats in Group Control $(n=5)$ were yoked to the reward schedule of paired rats in Group Omission, thus equating reward exposure.

Figure 1A presents the mean number of lever presses per minute to the CS + and CS - over the last day of sign-tracking acquisition (Last Acq) and over the course of negative automaintenance (Sessions 1-12). For automated measures of lever pressing (and food cup entries), we analyzed the entire $10 \mathrm{sec}$ of CS+ and CS - presentations. Both Omission and Control rats showed similarly high levels of lever pressing on the last day of sign-tracking

(C) 2016 Chang et al. This article is distributed exclusively by Cold Spring Harbor Laboratory Press for the first 12 months after the full-issue publication date (see http://learnmem.cshlp.org/site/misc/terms.xhtml). After 12 months, it is available under a Creative Commons License (AttributionNonCommercial 4.0 International), as described at http://creativecommons. org/licenses/by-nc/4.0/. 
A

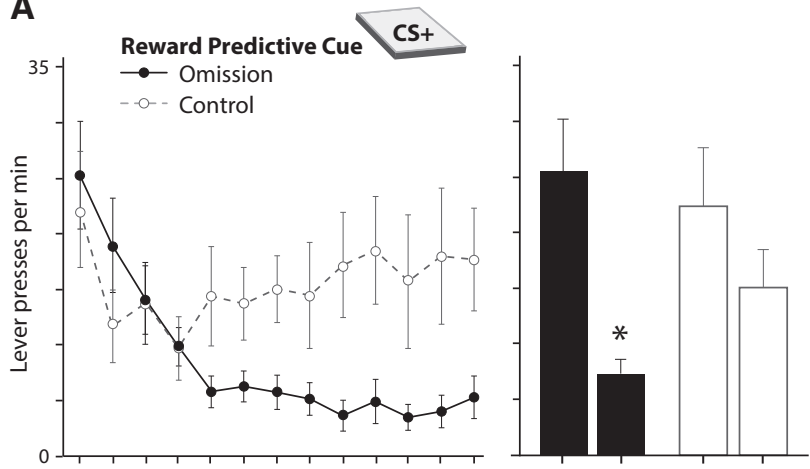

B

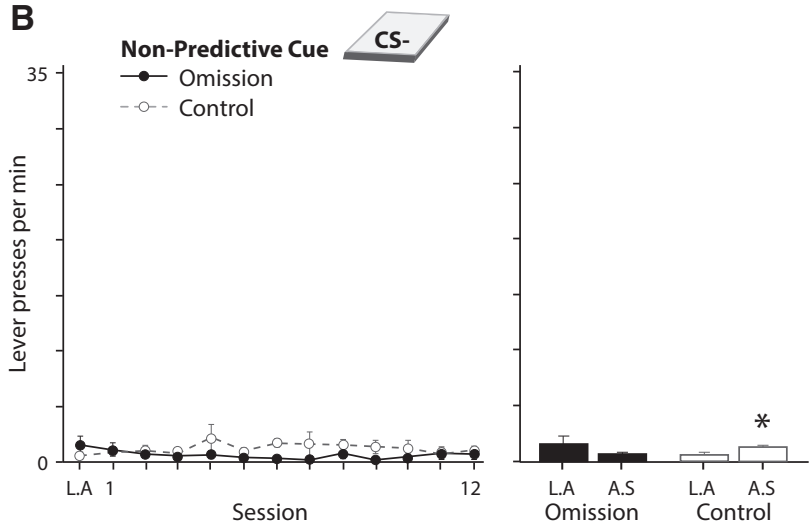

Figure 1. Negative automaintenance of sign-tracking. Lever presses per minute during, $(A)$ the reward predictive CS + lever insertion and, $(B)$ during the nonpredictive CS - lever insertion. Line graphs at left show data from the last acquisition day (LA) followed by the 12 procedure sessions for Omission rats (black lines and circles) and yoked Control rats (dashed lines and open circles). Shown at right are the last acquisition compared with the average of the 12 sessions (AS). Rats in the Omission group markedly reduced CS + lever pressing, but pressing still remained elevated above zero presses and above the minimal CS - presses. Control rats did not significantly change pressing, with the exception of a small elevation in CS - presses. (*) $P<0.05$ (LA to AS within group).

acquisition (Cue: $F_{(1,8)}=47.69, P<0.01$; Group $F_{(1,8)}=0.30, P=$ 0.60 ; interaction: $\left.F_{(1,8)}=0.11, P=0.75\right)$.

Over the course of negative automaintenance, Omission rats rapidly reduced behaviors that led to depression of the $\mathrm{CS}+$ lever once the negative contingency was imposed (Fig. 1A). CS+ pressing in yoked Control rats, however, remained statistically unchanged (Fig. 1A). Still, despite the negative contingency, Omission rats maintained higher levels of pressing to the CS+ than to the CS - throughout training (Fig. 1A,B). A 2 (Cue: CS+ versus $\mathrm{CS}-$ ) $\times 2$ (Group: Omission versus Control) $\times 12$ (Session) ANOVA confirmed a main effect of Cue $\left(F_{(1,8)}=36.59\right.$, $P<0.01)$ and a marginal effect of Group $\left(F_{(1,8)}=5.03, P=0.06\right)$, but no effect of Session $\left(F_{(11,88)}=1.15, P=0.34\right)$. In addition, there were Group $\times$ Session $\left(F_{(11,88)}=4.46, P<0.01\right)$ and Cue $\times$ Group $\times$ Session interactions $\left(F_{(11,88)}=4.14, P<0.01\right)$. The Cue $\times$ Group and Cue $\times$ Session interactions did not reach statistical significance (largest $\left.F_{(1,8)}=4.37, P=0.07\right)$. Concerning the nature of the Cue $\times$ Group $\times$ Session interaction, ANOVAs run over four-session blocks of negative automaintenance (Sessions $1-4,5-8$, and 9-12) confirmed that Omission and Control rats showed comparable levels of discriminative pressing to the CS+ and CS - over the first block (Sessions 1-4) (Cue $\times$ Group: $\left.F_{(1,8)}<0.01, P=0.95\right)$. However, Control rats showed higher lev- els of pressing than Omission rats to the CS+ over the second (Sessions 5-8) and third (Sessions 9-12) blocks of training (Sessions 5-8, Cue $\times$ Group: $F_{(1,8)}=8.07, P=0.02$; Sessions 9-12, Cue $\times$ Group: $\left.F_{(1,8)}=5.65, P=0.045\right)$.

We further evaluated the degree of sign-tracking within each group. For Control rats, the ANOVA confirmed a main effect of Cue $\left(F_{(1,4)}=18.68, P=0.01\right)$ but no effect of Session $\left(F_{(11,44)}=\right.$ $0.91, P=0.54)$ or Cue $\times$ Session interaction $\left(F_{(11,44)}=0.83, P=\right.$ $0.61)$. For Omission rats, there were main effects of Cue $\left(F_{(1,4)}=34.54, P<0.01\right)$ and Session $\left(F_{(11,44)}=8.41, P<0.01\right)$, as well as a Cue $\times$ Session interaction $\left(F_{(11,44)}=9.59, P<0.01\right)$. In addition, separate ANOVAs over four-session blocks of negative automaintenance for each group confirmed main effects of Cue for all three blocks (Control: smallest $F_{(1,4)}=10.37, P=$ 0.03; Omission: smallest $F_{(1,4)}=9.11, P=0.04$ ).

These data indicate that rats under the yoked Control condition maintained stable levels of sign-tracking to the CS + across the $12 \mathrm{~d}$ under the new reward contingency. In contrast, rats under the Omission condition starkly reduced lever pressing, but still retained it at a low level. This conclusion was supported further by findings from comparing, within-subjects, the last sign-tracking acquisition day (LA) to the average of sessions (AS) of negative automaintenance (Fig. 1A, right): the Omission group showed a significant reduction in CS + lever presses $(P=0.01)$, but the Control group did not $(P=0.21)$. CS - lever pressing was low throughout for both groups, though there was a marginal but significant rise in $\mathrm{CS}-$ pressing in Control rats $(P=0.04$; Fig. 1B, right).

However, lever depression measures do not capture the full repertoire of a sign-tracking CR, and our analyses of the CR topography suggested a different story. Stimulus approach and consummatory behaviors were video-scored during every fifth $\mathrm{CS}+$ and CS - presentation (Mahler and Berridge 2009) for the last acquisition day and sessions 4,8 , and 12 . Behaviors were sampled every $2 \mathrm{sec}$ for the duration of each CS presentation. Stimulus consummatory behaviors included lever grasps (grabs of the lever with forepaws) and lever bites (active bites or nibbles of the lever). Stimulus approach included lever orienting (head movement in close proximity toward the lever), lever sniffs (at least one sniff action in close proximity of the lever), and nonconsummatory lever contacts (bodily touching of the lever without biting or grasping). Because rats have to approach the lever in order to show a consummatory behavior, an approach behavior was also counted if a rat was grasping or biting the lever. Behavior counts were then totaled for each session and added by category.

On the last acquisition day, Omission and Control rats displayed similarly high levels of approach behaviors during the CS + but not the CS - [Cue $\left(F_{(1,8)}=133.56, P<0.01\right)$, no effect of Group $\left(F_{(1,8)}=1.28, P=0.29\right)$, or interaction $\left(F_{(1,8)}=2.46\right.$, $P=0.16)]$. The groups were also similar in stimulus consummatory behaviors on that day, which were more frequent on the CS+ than the CS - lever, due to the high levels of consummatory responses to the CS+ and minimal response generally to the CS(Cue: $F_{(1,8)}=24.77, P<0.01$; Group: $F_{(1,8)}=0.51, P=0.50$; interaction: $\left.F_{(1,8)}=0.51, P=0.50\right)$.

Despite a dramatic decrease in lever presses over the course of negative automaintenance, Omission rats continued to approach the sucrose-paired lever at comparable rates to Control rats. Approach behaviors remained high for the CS+ for both groups, while approach to the CS - remained low [(Cue: $F_{(1,8)}=$ 34.15, $P<0.01$; no effect of Group: $F_{(1,8)}=0.46, P=0.52$, Session $F_{(2,16)}=1.55, P=0.24$, Cue $\times$ Group: $F_{(1,8)}=1.73, P=$ 0.23 , or other interactions: largest $F=1.74, P=0.21)]$. In comparing behaviors within each group, Omission rats showed a greater number of approach behaviors to the CS + than $\mathrm{CS}-\left(F_{(1,4)}=\right.$ 36.63, $P<0.01)$, as did Control rats $\left(F_{(1,4)}=7.89, P=0.048\right)$. 
A

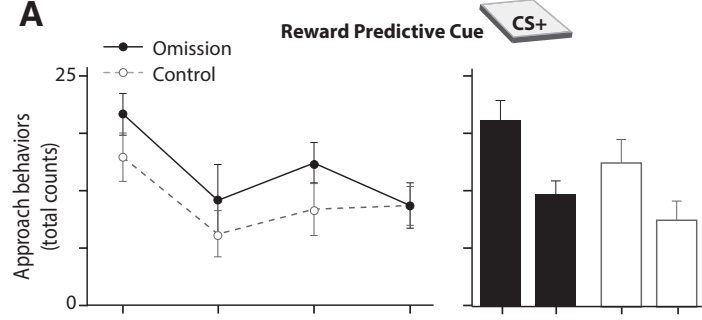

B
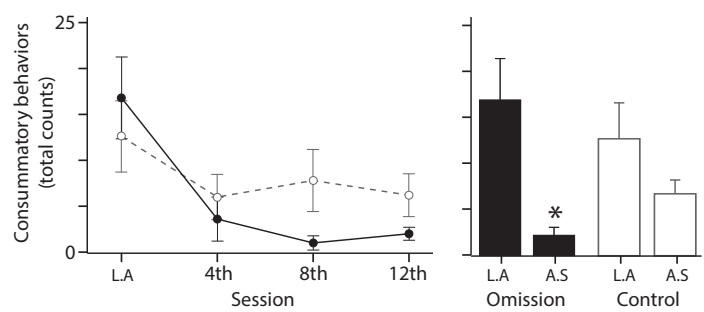

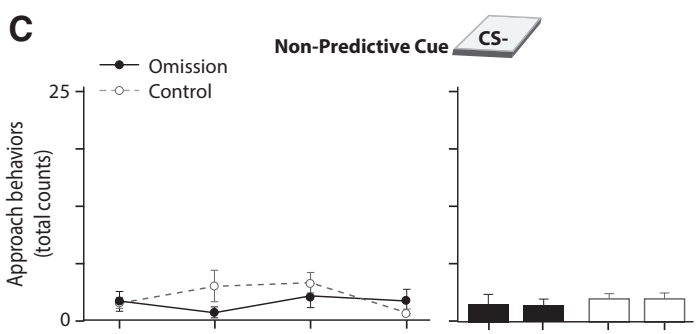

D

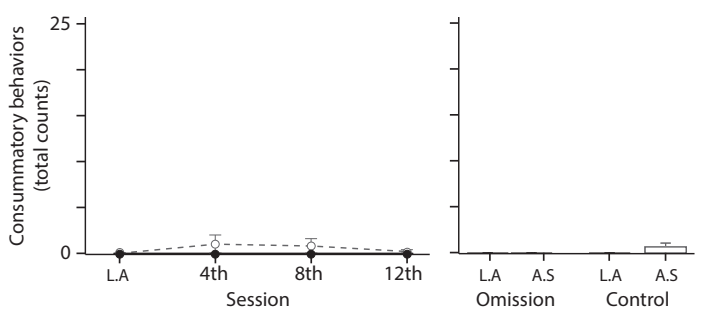

Figure 2. Omission procedure dissociates approach versus consummatory features of sign-tracking. $(A)$ Approach behaviors directed to the CS + lever (orient, sniff, contact) on the last acquisition session and sessions 4, 8, and 12 of negative automaintenance for Omission and Control rats. Bar graph shows averaged sessions 4, 8, and 12 (AS) compared with the last acquisition session (LA). (B) Consummatory behaviors directed to the CS+ lever (grasp and bite). Omission rats increased CS+ approach behaviors and decreased consummatory behaviors that could lead to lever depression and reward cancellation, thus maintaining a fairly high level of CS+ engagement relative to Control rats but reallocating it to mainly approach behaviors. $\left(^{*}\right) P<0.05$ (LA to AS within group for CS + ). (C) Approach behaviors directed to the CS - lever. (D) Consummatory behaviors directed to the CS lever. No comparisons between LA and AS were significant for CS - .

These trends were further supported by repeated-measures ANOVAs comparing the last acquisition day to the average of negative automaintenance behavior: Omission rats did not significantly change their $\mathrm{CS}+$ approach $(P=0.07$; Fig. $2 \mathrm{~A})$, nor did Control rats $(P=0.10$; Fig. $2 \mathrm{~A})$, and neither Group changed their CS - approach ( $P$ 's $>0.05)$ (Fig. 2C).

Stimulus consummatory behaviors followed a similar trend (Fig. 2B). Overall, rats showed a greater number of consummatory behaviors to the $\mathrm{CS}+$ than $\mathrm{CS}-$, but there were moderate group differences (Cue: $F_{(1,8)}=7.82, P=0.02$; Group: $F_{(1,8)}=4.11, P=$ 0.08; Session: $F_{(2,16)}=0.25, P=0.78$; all interactions: largest $F=$ $1.68, P=0.23)$. Nevertheless, under direct repeated-measures comparison to the last acquisition day, Omission rats showed significantly reduced consummatory actions $(P=0.027)$ on average during negative automaintenance, which were $87 \%$ reduced. Control rats' consummatory behaviors did not change significantly ( $P=0.20 ; 47 \%$ reduced). Neither group changed their consummatory response to the $\mathrm{CS}-\left(P^{\prime} \mathrm{s}>0.05\right)$ (Fig. 2$)$.

We further explored these effects by assessing the contribution of each single component of the CR to the total number of behaviors exhibited using nonparametric Kruskal-Wallis tests (Fig. 3). For this, we simply counted each observed instance of a behavior. Omission rats showed an elevation in both their proportion of lever sniffing $(P=0.03)$, which increased from $0 \%$ to $27 \%$ of the total $\mathrm{CR}$, and orienting $(P=0.03)$, which increased from $5 \%$ to $25 \%$ of the total CR (Fig. 3A,B). Conversely, the proportion of the CR that was lever bites declined dramatically from $77 \%$ to $17 \%(P=0.01)$ (Fig. $3 \mathrm{~A}, \mathrm{~B})$. These changes were at the heart of a robust restructuring of the approach versus consummatory sign-tracking CRs made to the CS + that occurred from the last acquisition day through the negative automaintenance sessions (Fig. 3B). Overall, on the last acquisition day, $82 \%$ of the CR took the form of approach-and-consume behaviors (mainly biting). During negative automaintenance, this proportion reversed, with a nearly identical $82.5 \%$ of the CR being composed instead of approach-only behaviors. In comparison, Control rats did not show a change in their proportion of any CS + sign-tracking CR, instead exhibiting mostly lever bites throughout testing (Fig. $3 \mathrm{~A}, \mathrm{~B})$. What this suggests is that Omission rats did not cease responding once they exhibited an initial approach CR. Instead, they continued to exhibit approach-specific behaviors like orientations and sniffs, while not subsequently emitting a consummatory response. Thus, the frequency of approach-only behaviors rose for this group. In contrast, Control rats continued emitting consummatory responses, and thus approach-only counts like orientations and sniffs were comparatively low.

Percent of time in the food cup during CS presentations was also assessed under the possibility that Omission rats may have engaged more with the food source (i.e., goal-tracking) when lever presses canceled reward. This was not the case: both Omission and Control rats maintained fairly consistent and low levels of food cup time (ANOVA on Cue $\times$ Group $\times$ Session: largest main effect $F_{(1,8)}=2.54, P=0.15$; largest interaction $F_{(11,88)}=1.55, \quad P=$ 0.13). When comparing the last acquisition day to the average of the negative automaintenance sessions, Omission rats did show a moderate increase in food cup time during the CS $+(P=$ 0.036), which appeared related to a low level of food cup time on the last acquisition day (Supplemental Fig. 1). Still, food cup entry time during negative automaintenance accounted for only $12.46 \%$ of their time during the CS+, and food cup time during the CS - was comparable at $12.82 \%$. No group changed food cup entry time behavior during the CS $-\left(P^{\prime} \mathrm{s}>0.05\right)$. Hand-scored food cup orientations during the CS+ and CSwere also unchanged and similar between groups $\left(P^{\prime} \mathrm{s}>0.05\right)$ (Supplemental Fig. 1).

Collectively, these findings support the conclusion that signtracking rats exposed to an omission procedure reduce behaviors that lead to reward cancellation (lever depression) including consummatory behaviors like biting, but they concomitantly maintain approach behaviors like orientations and sniffs. Indeed, when aggregating hand-scored consummatory and approach behaviors, Omission rats showed a relatively moderate $41 \%$ decline in sign-tracking from the last acquisition day that was essentially identical to the decline in Control rats (40\%). This equivalence 
A
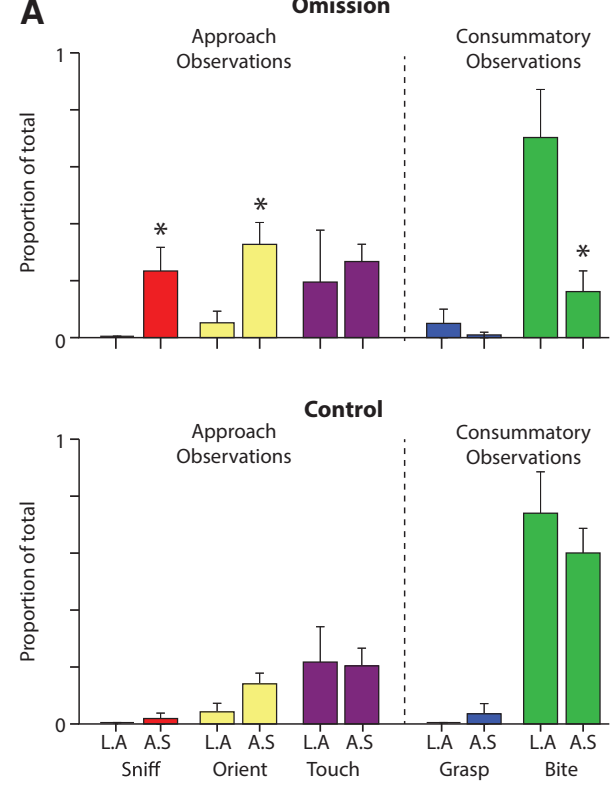

B Omission

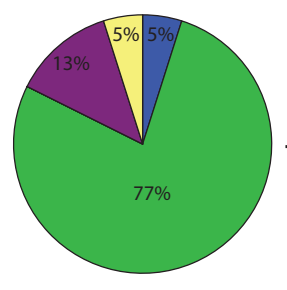

L.A

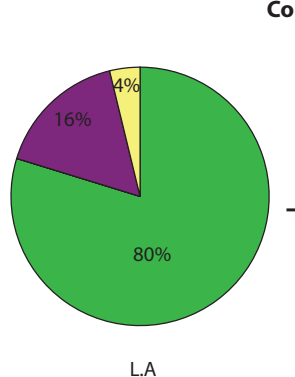

L.A

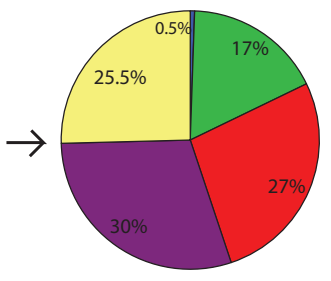

A.S

Control

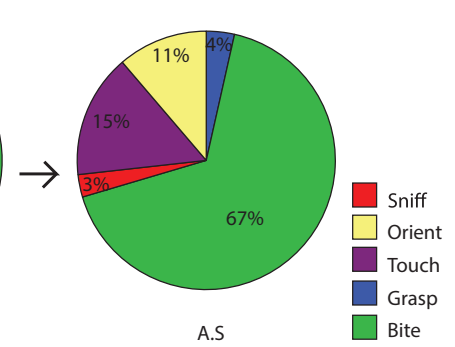

Figure 3. $C S+$ approach and consummatory behavior microstructure. $(A)$ Proportion of sign-tracking responses to the CS + on the last acquisition (LA) and negative automaintenance days (AS) that were sniffs (red), orientations (yellow), touches (purple), grasps (blue), and bites (green). Top graph shows the Omission group, bottom shows the Control group. $\left(^{*}\right) P<0.05$ (LA to AS within group). (B) Pie charts representing the proportion of responses on these days with approach and consummatory segments denoted.

contrasted sharply to the Omission rats' larger 71\% decline in automated lever press counts, while Controls only reduced lever press counts by $22 \%$. Thus $\sim 60 \%$ of the acquired sign-tracking CR persisted despite the omission schedule, and the persistence was similar to Controls. This suggests that the CS+ retained much of its motivational value and that its expression in behavior was highly flexible.

Although Locurto et al. (1976) observed differences in response topography between rats placed on sign-tracking and omission schedules, these differences were not quantified. Based on a near-full reduction in lever contacts in their study, Locurto et al. (1976) argued that omission training was ineffective at maintaining responding to the lever. However, our data suggest that sign-tracking can be robustly maintained under omission training as demonstrated by a loss of terminal (consummatory) behaviors yet maintenance in approach-only behaviors.

Approach behaviors were not put under the omission contingency, and therefore we do not know what their sensitivity would be. Similarly, we recognize the potential role for stimulusresponse associations in the residual lever press responses. Nevertheless, we suggest the maintenance of approach behaviors are best captured by incentive motivation concepts, which suggest that such sign-tracking CRs occur because of a motivational attraction to the $\mathrm{CS}+$, a motivation that can become decoupled from trial-to-trial variations in reward outcome. The fact that rats persisted in engaging with the $\mathrm{CS}+$ instead of favoring the food cup lends further support to the argument here that the incentive value of the CS+ remained high.

In the brain, limbic circuits have been implicated in signtracking (Cardinal et al. 2002; Mahler and Berridge 2009; Flagel et al. 2010; Chang et al. 2012a,b, 2015; Saunders and Robinson 2012; Chang and Holland 2013). A fruitful effort would be to resolve the neural mechanisms by which rats adaptively modify their responses when CS-CR-US conditions change but CS incentive salience remains strong. This question gets to the heart of an issue facing efforts to understand the brain basis of addictive behaviors, in which addicts can exhibit flexibility in their pursuit of drug-associated stimuli. Evidence here indicates that the ability of a salient cue to pull in behavior can be rooted in a motivational process but not necessarily tied down to a specific behavioral routine. Such persistence-with-flexibility features may be useful, quantifiable targets for addiction research.

\section{Acknowledgments}

We thank Dr. Peter Holland for facilities used in data collection, as well as for helpful comments on this manuscript. We also thank Dr. Kent Berridge for helpful manuscript comments. This work was supported by National Institutes of Health grant MH53667 (to P. Holland), National Institutes of Health grant MH106178 (S.E.C.), and a Whitehall Foundation research grant 2014-05-77 (to K.S.S.).

\section{References}

Atnip GW. 1977. Stimulus- and response-reinforcer contingencies in autoshaping, operant, classical, and omission training procedures in rats. J Exp Anal Behav 28: 59-69.

Berridge KC. 2004. Motivation concepts in behavioral neuroscience. Physiol Behav 81: 179-209.

Boakes R. 1977. Performance on learning to associate a stimulus with positive reinforcement. In Operant-Pavlovian interactions (ed. Davis $\mathrm{H}$, Hurwitz H), pp. 67-97. Lawrence Erlbaum Associates, Hillsdale, NJ.

Brown PL, Jenkins HM. 1968. Auto-shaping of the pigeon's key-peck. J Exp Anal Behav 11: 1-8.

Cardinal RN, Parkinson JA, Lachenal G, Halkerston KM, Rudarakanchana N, Hall J, Morrison CH, Howes SR, Robbins TW, Everitt BJ. 2002. Effects of selective excitotoxic lesions of the nucleus accumbens core, anterior cingulate cortex, and central nucleus of the amygdala on autoshaping performance in rats. Behav Neurosci 116: $553-567$.

Chang SE, Holland PC. 2013. Effects of nucleus accumbens core and shell lesions on autoshaped lever-pressing. Behav Brain Res 256: 36-42.

Chang SE, Wheeler DS, Holland PC. 2012a. Effects of lesions of the amygdala central nucleus on autoshaped lever pressing. Brain Res 1450: 49-56.

Chang SE, Wheeler DS, Holland PC. 2012b. Roles of nucleus accumbens and basolateral amygdala in autoshaped lever pressing. Neurobiol Learn Mem 97: 441-451. 
Chang SE, Todd TP, Bucci DJ, Smith KS. 2015. Chemogenetic manipulation of ventral pallidal neurons impairs acquisition of sign-tracking in rats. Eur J Neurosci 42: 3105-3116.

Davey GC, Oakley D, Cleland GG. 1981. Autoshaping in the rat: effects of omission on the form of the response. J Exp Anal Behav 36: $75-91$.

Eldridge GD, Pear JJ. 1987. Topographical variations in behavior during autoshaping, automaintenance, and omission training. J Exp Anal Behav 47: 319-333.

Flagel SB, Clark JJ, Robinson TE, Mayo L, Czuj A, Willuhn I, Akers CA, Clinton SM, Phillips PE, Akil H. 2010. A selective role for dopamine in stimulus-reward learning. Nature 469: 53-57.

Hearst E, Jenkins H. 1974. Sign-tracking: the stimulus-reinforcer relation and directed action. Monograph of the Psychonomic Society, Austin.

Huys QJ, Tobler PN, Hasler G, Flagel SB. 2014. The role of learningrelated dopamine signals in addiction vulnerability. Prog Brain Res 211: $31-77$.

Jenkins HM, Moore BR. 1973. The form of the auto-shaped response with food or water reinforcers. J Exp Anal Behav 20: 163-181.

Lajoie J, Bindra D. 1976. An interpretation of autoshaping and related phenomena in terms of stimulus-incentive contingencies alone. Can J Psychol 30: 157-173.

Locurto C, Terrace HS, Gibbon J. 1976. Autoshaping, random control, and omission training in the rat. J Exp Anal Behav 26: 451-462.

Mahler SV, Berridge KC. 2009. Which cue to "want?" Central amygdala opioid activation enhances and focuses incentive salience on a prepotent reward cue. J Neurosci 29: 6500-6513.

Robinson MJ, Berridge KC. 2013. Instant transformation of learned repulsion into motivational "wanting". Curr Biol 23: 282-289.
Robinson TE, Yager LM, Cogan ES, Saunders BT. 2014. On the motivational properties of reward cues: individual differences. Neuropharmacology 76(Pt B): 450-459.

Saunders BT, Robinson TE. 2012. The role of dopamine in the accumbens core in the expression of Pavlovian-conditioned responses. Eur J Neurosci 36: 2521-2532.

Schwartz B, Williams DR. 1972a. The role of the response-reinforcer contingency in negative automaintenance. J Exp Anal Behav 17: $351-357$.

Schwartz B, Williams DR. 1972b. Two different kinds of key peck in the pigeon: some properties of responses maintained by negative and positive response-reinforcer contingencies. J Exp Anal Behav 18: $201-216$

Skinner BF. 1992. 'Superstition' in the pigeon. 1948. J Exp Psychol Gen 121: $273-274$.

Stiers M, Silberberg A. 1974. Lever-contact responses in rats: automaintenance with and without a negative response-reinforcer dependency. J Exp Anal Behav 22: 497-506.

Tomie A, Grimes KL, Pohorecky LA. 2008. Behavioral characteristics and neurobiological substrates shared by Pavlovian sign-tracking and drug abuse. Brain Res Rev 58: 121-135.

Williams DR, Williams H. 1969. Auto-maintenance in the pigeon: sustained pecking despite contingent non-reinforcement. J Exp Anal Behav 12: 511-520.

Woodard WT, Ballinger JC, Bitterman ME. 1974. Autoshaping: Further study of "negative automaintenance." J Exp Anal Behav 22: 47-51.

Received December 28, 2015; accepted in revised form January 21, 2016. 


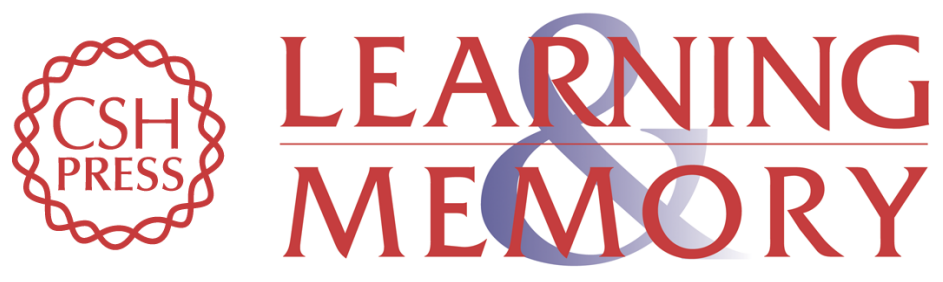

\section{An omission procedure reorganizes the microstructure of sign-tracking while preserving incentive salience}

Stephen E. Chang and Kyle S. Smith

Learn. Mem. 2016, 23:

Access the most recent version at doi:10.1101/Im.041574.115

\section{Supplemental http://learnmem.cshlp.org/content/suppl/2016/03/10/23.4.151.DC1 Material}

References This article cites 26 articles, 1 of which can be accessed free at: http://learnmem.cshlp.org/content/23/4/151.full.html\#ref-list-1

Creative This article is distributed exclusively by Cold Spring Harbor Laboratory Press for the Commons first 12 months after the full-issue publication date (see

License http://learnmem.cshlp.org/site/misc/terms.xhtml). After 12 months, it is available under a Creative Commons License (Attribution-NonCommercial 4.0 International), as described at http://creativecommons.org/licenses/by-nc/4.0/.

Email Alerting Receive free email alerts when new articles cite this article - sign up in the box at the Service top right corner of the article or click here. 